\title{
REFORMA DA EDUCAÇÃO PROFISSIONAL OU AJUSTE AO REGIME DE ACUMULAÇÃO FLEXÍVEL?
}

\author{
REFORM OF PROFESSIONAL EDUCATION OR ADJUSTING TO THE FLEXIBLE ACCUMULATION \\ SYSTEM?
}

\section{Acacia Zeneida Kuenzer 1}

Resumo Este artigo foi produzido com a finalidade de estimular o debate acerca das políticas e programas que vêm sendo oferecidos aos trabalhadores desde o decreto $\mathrm{n}^{\circ} 2.208 / 97$, justificados pelo discurso da inclusão, como estratégia de enfrentamento do desemprego estrutural que caracteriza o regime de acumulação flexível. Dada a expressiva produção já existente sobre os impactos, perversos, do referido decreto, optou-se por apresentar, em síntese, os resultados das pesquisas que temos realizado nos últimos anos, com a finalidade de compreender as categorias que regem estas políticas e ofertas neste regime de acumulação. Para tanto, o artigo se divide em duas partes; na primeira, são analisadas as categorias que configuram a educação profissional na acumulação flexível, com ênfase nos arranjos flexíveis de competências diferenciadas, para os quais contribuem decisivamente a educação geral e as novas combinações entre conhecimentos científicos e tácitos, em decorrência da intelectualização das competências. Na segunda parte, são analisadas as políticas de educação profissional que explicitam a ação do Estado no regime de acumulação flexível: a crescente privatização apoiada em legislação específica, a fragmentação e a precarização dos percursos formativos.

Palavras-chave educação profissional; política educacional; precarização do trabalho e da educação.
Abstract The purpose of this article was to encourage the debate on the policies and programs that have been being offered to workers since the enactment of decree 2.208/97, justified by the discourse of inclusion, as a strategy to face the structural unemployment that characterizes the flexible accumulation system. Given the expressive production that already exists on the perverse impacts of the abovementioned decree, an option was made to present, in synthesis, the results of the survey we have been undertaking in the past few years seeking to understand the categories that govern these policies and offers in this accumulation system. To do so, the article is divided into two parts; the first analyzes the categories that configure professional education in flexible accumulation emphasizing the flexible arrangements of differentiated competencies, to which general education and new scientific ant tacit knowledge combinations make decisive contributions as a result of competency intellectualization. The second part, meanwhile, analyzes the professional education policies that pinpoint the State's action in the flexible accumulation system: the increasing privatization movement underpinned by specific legislation, fragmentation, and the loss of quality in the paths that lead to qualification.

Keywords professional education; educational policie; loss of quality in work and education. 


\section{Introdução}

Este texto tem por objetivo apresentar, de forma sintética, os resultados dos estudos que temos levado a efeito na última década, sobre as políticas e programas de educação profissional que têm sido destinados aos que vivem do trabalho. Considerando a existência de ampla e qualificada produção sobre a história e as políticas de educação profissional, optou-se por elencar alguns pontos que estimulem a discussão acerca dos rumos que estas políticas e propostas tomam no regime de acumulação flexível, bem como acerca dos espaços possíveis de construção de alternativas que atendam ao projeto dos que vivem do trabalho (Kuenzer, 2003a, 2003b, 2006, 2007).

Inicialmente, é preciso que se elucidem os pressupostos que fundamentam a discussão levada a efeito neste artigo. Com base nas clássicas categorias que definem a ontologia e a epistemologia que sustenta a área Trabalho e Educação, partimos do pressuposto que, considerando a centralidade do trabalho, no modo de produção capitalista, todas as formas de inclusão são sempre subordinadas, concedidas, porque atendem às demandas do processo de acumulação. Ou, como afirma Oliveira (2004), que o círculo entre exclusão e inclusão subordinada é condição de possibilidade dos processos de produção e reprodução do capital, sendo constitutivo lógico necessário das sociedades capitalistas modernas, ou seja, são faces inseparáveis da mesma moeda.

Assim, as políticas e programas de educação profissional, tomando a categoria exclusão para designar desempregados e populações em situação de risco social, quando propõem como objetivo a inclusão social, não ultrapassam o âmbito da inclusão concedida, ou como a temos chamado, inclusão excludente, sempre subordinada à lógica da acumulação. Este pressuposto não elide a categoria contradição, derivada da relação entre capital e trabalho, a partir da qual se admite que, além da dimensão exploradora, o trabalho e os processos educativos por ele determinados inscrevem-se também na esfera da formação humana, manifestando uma positividade que aponta possibilidades de transformação das relações sociais. Embora, em tese, este pressuposto tenha sustentação histórica e teórica, os limites e possibilidades da educação profissional precisam ser adequadamente delineados no regime de acumulação flexível, tanto para superar o imobilismo quanto para rejeitar uma visão romantizada, igualmente conservadora.

A tese que orienta esta análise, com base nos pressupostos teóricometodológicos do materialismo histórico, e que, acreditamos, resume a pedagogia no regime de acumulação flexível, já foi formulada em outros textos: do ponto de vista do mercado, ocorre um processo de exclusão da força de trabalho dos postos reestruturados, para incluí-la de forma precarizada em outros pontos da cadeia produtiva. Já do ponto de vista da educação, se estabelece 
um movimento contrário, dialeticamente integrado ao primeiro: por força de políticas públicas 'professadas' na direção da democratização, aumenta-se a inclusão em todos os pontos da cadeia, mas se precarizam os processos educativos, que resultam em mera oportunidade de certificação, os quais não asseguram nem inclusão nem permanência. Em resumo, do lado do mercado, um processo de exclusão includente, que tem garantido diferenciais de competitividade para os setores reestruturados através da combinação entre integração produtiva, investimento em tecnologia intensiva de capital e de gestão e consumo precarizado da força de trabalho. Do lado do sistema educacional e de educação profissional, um processo de inclusão que, dada a sua desqualificação, é excludente e, exatamente por isso, alimenta as cadeias produtivas com competências que são consumidas diversamente e, de modo geral, predatoriamente (Kuenzer, 2006).

Esclarecidos os pressupostos, apresentam-se a seguir algumas conclusões a que chegamos nas pesquisas que vimos desenvolvendo nos últimos anos, com vistas a estimular o debate e a compreensão dos espaços possíveis de avanço.

A partir deste ponto do texto, apresentamos uma primeira síntese, para discussão, das dimensões que entendemos caracterizar as relações entre educação e trabalho na acumulação flexível, proveniente das pesquisas que realizamos na cadeia coureiro-calçadista e em empresas reestruturadas do setor de gás, petróleo e energia, com base nos pressupostos enunciados.

\section{Arranjos flexíveis de competências diferenciadas}

Diferentemente do que ocorria no taylorismo/fordismo, onde as competências eram desenvolvidas com foco em ocupações previamente definidas e relativamente estáveis, a integração produtiva se alimenta do consumo flexível de competências diferenciadas, que se articulam ao longo das cadeias produtivas. Estas combinações não seguem modelos preeestabelecidos, sendo definidas e redefinidas segundo as estratégias de contratação e subcontratação que são mobilizadas, tendo em vista atender, de forma competitiva, às necessidades do mercado e, assim, assegurar as maiores margens de lucro possíveis, que, no processo de internacionalização, tendem a ser estreitadas. Em decorrência, só podem ser apreendidas por meio de análise da dinâmica da integração produtiva como totalidade complexa em permanente processo de construção e reconstrução, a partir da lógica da acumulação flexível.

Conseqüentemente, os arranjos flexíveis, em substituição à polarização de competências, não podem ser compreendidos como mera oposição, rígida e formal, entre os que têm formação científico-tecnológica avançada, e 
por isso se incluem, e a grande massa de trabalhadores precariamente escolarizados, cuja força de trabalho é consumida predatoriamente em trabalhos desqualificados, ou é excluída. São combinações que ora incluem, ora excluem trabalhadores com diferentes qualificações, de modo a constituir corpos coletivos de trabalho dinâmicos, por meio de uma rede que integra diferentes formas de subcontratação e trabalho temporário e que, ao combinar diferentes estratégias de extração de mais-valia, assegura a realização da lógica mercantil.

Se há combinação entre trabalhos desiguais e diferenciados ao longo das cadeias produtivas, há demandas diferenciadas, e desiguais, de qualificação dos trabalhadores; contudo, os arranjos são definidos pelo consumo da força de trabalho necessário, e não a partir da qualificação. O foco não é a qualificação em si, mas como ela se situa em dada cadeia produtiva, com o que ela se relativiza. A priori, não há como afirmar que certo trabalhador é ou não qualificado, uma vez que isso se define a partir de sua inclusão na cadeia; ou seja, a dimensão de relação social da qualificação se superlativiza na acumulação flexível, que avança na centralização do trabalho abstrato.

Dessa forma, trabalhadores qualificados que estão incluídos em um determinado arranjo poderão não estar em outros, ou os que são qualificados para certos elos da cadeia não o serão necessariamente para outros; estar incluído a partir de uma dada qualificação não assegura que não esteja excluído em outros momentos e vice-versa, dependendo das necessidades do sistema produtivo. O que determina a inclusão na cadeia, portanto, não é a presença ou a ausência de qualificação, mas as demandas do processo produtivo que combinam diferentes necessidades de ocupação da força de trabalho, a partir da tarefa necessária à realização da mercadoria.

Daí o caráter 'flexível' da força de trabalho; importa menos a qualificação prévia do que a adaptabilidade, que inclui tanto as competências anteriormente desenvolvidas, cognitivas, práticas ou comportamentais, quanto a competência para aprender e para submeter-se ao novo, o que supõe subjetividades disciplinadas que lidem adequadamente com a dinamicidade, com a instabilidade, com a fluidez.

\section{A educação geral como substituta da formação profissional no nível básico}

A formação de subjetividades flexíveis, tanto do ponto de vista cognitivo quanto ético, se dá, predominantemente, pela mediação da educação geral; é por meio dela, disponibilizada de forma diferenciada por origem de classe, que os que vivem do trabalho adquirem conhecimentos genéricos que lhes permitirão exercer, e aceitar, múltiplas tarefas no mercado flexibilizado. Ser multitarefa, neste caso, implica exercer trabalhos simplificados, repetitivos, 
fragmentados, para os quais seja suficiente um rápido treinamento, de natureza psicofísica, a partir de algum domínio de educação geral, o que não implica necessariamente o acesso à educação básica completa.

Neste sentido, a educação geral, assegurada pelos níveis que compõem a educação básica, tem como finalidade dar acesso aos conhecimentos fundamentais e às competências cognitivas mais simples, que permitam a integração à vida social e produtiva em uma organização social com forte perfil científico-tecnológico, um dos pilares a sustentar o capitalismo tardio, na perspectiva do disciplinamento do produtor/consumidor; e, por isso, a burguesia não só a disponibiliza, mas a defende para os que vivem do trabalho.

Ser flexível, para estes trabalhadores, significa adaptar-se ao movimento de um mercado que inclui/exclui, segundo as necessidades do regime de acumulação. A competência, nos pontos desqualificados das cadeias produtivas, resume-se ao conhecimento tácito, demandado pelo trabalho concreto. Não há, para estes trabalhadores que atuam nos setores precarizados, demandas relativas ao desenvolvimento da competência de trabalhar intelectualmente em atividades de natureza científico-tecnológica, em virtude do que não se justifica formação avançada.

Para os que exercerão atividades complexas na ponta qualificada das cadeias produtivas, a educação básica é rito de passagem para a educação científico-tecnológica e sócio-histórica de alto nível. Nestes casos, a flexibilidade, atributo geralmente exercitado internamente às firmas, advém da capacidade de trabalhar intelectualmente e atuar praticamente, para usar a expressão gramsciana (Gramsci, 1978), estabelecendo-se uma maior integração entre concepção e atuação. Ou, como afirma Antunes (2005), a nova fase do capital 're-transfere' o saber fazer para o trabalho, apropriando-se de sua dimensão intelectual, procurando envolver mais intensamente a subjetividade operária. Ao mesmo tempo, transfere parte do saber intelectual para as máquinas informatizadas, que se tornam mais inteligentes, reproduzindo parte das atividades a elas transferidas pelo saber intelectual.

Ser multitarefa, neste caso, significa a capacidade de adaptar-se a múltiplas situações complexas e diferenciadas, que demandam o desenvolvimento de competências cognitivas mais sofisticadas que permitam a solução de problemas com rapidez, originalidade e confiabilidade. Para tanto, há que assegurar formação avançada, que articule as dimensões geral e específica.

A segunda categoria, portanto, que configura a dualidade na acumulação flexível é a distribuição desigual e diferenciada de educação que, ao contrário do que ocorria no taylorismo/fordismo, valoriza a educação básica para os que vivem do trabalho, como condição para a formação flexível, e a educação específica, de natureza científico-tecnológica e sócio-histórica, para os que vão exercer o trabalho intelectual, de modo a assegurar que a 
posse do que é estratégico, nesse caso o conhecimento que permite inovação, permaneça com o capital.

A estratégia por meio da qual o conhecimento é disponibilizado/negado, segundo as necessidades desiguais e diferenciadas dos processos de trabalho integrados, é o que temos chamado de inclusão excludente na ponta da escola. Ao invés da explícita negação das oportunidades de acesso à educação continuada e de qualidade, há uma aparente disponibilização das oportunidades educacionais, por meio de múltiplas modalidades e dife-rentes naturezas, que se caracterizam por seu caráter desigual e, na maioria das vezes, meramente certificatório, que não asseguram domínio de conhe-cimentos necessários ao desenvolvimento de competências cognitivas complexas vinculadas à autonomia intelectual, ética e estética.

Conclui-se, desta rápida exposição, que a relativização da qualificação com foco na ocupação permite a formação de um maior contingente de trabalhadores com mais educação, se possível básica completa e até superior, o que viabilizará maior flexibilidade em seu uso combinado ao longo das cadeias produtivas. Desta forma, caracteriza-se menor dependência do capital em relação ao trabalho qualificado, que, pelo uso flexível, fica mais vulnerável.

Já o conhecimento científico tecnológico, integrado à cultura e ao trabalho, por seu caráter estratégico para a competitividade por meio da inovação, tem sua distribuição mais controlada e, embora também seja disponibilizado de forma diferenciada para atender aos arranjos flexíveis, tem caráter mais elitizado.

Enfim, a relativização da qualificação pela banalização das competências, ao tempo que liberta o capital das competências específicas, permitelhe maior liberalidade quanto à oferta de educação mais ampliada, o que, inclusive, passa a defender... desde, é claro, que mantenha privada a propriedade do conhecimento estratégico à acumulação, qual seja, o conhecimento científico-tecnológico e sócio-histórico de ponta, reservado aos intelectuais seus prepostos.

\section{Conhecimento tácito e conhecimento científico: a mediação da educação como resposta à intelectualização das competências}

Já se afirmou, com base em pesquisas realizadas nos últimos 12 anos, que no taylorismo/fordismo a competência, predominantemente psicofísica e fragmentada, advinda antes da experiência do que da relação com o conhecimento sistematizado, tinha natureza predominantemente tácita, para a maioria das ocupações. Este conhecimento se insere no âmbito das dimensões subjetivas 
do trabalho, constituindo-se de formas inconscientes, não sistematizadas, não transferíveis e geralmente não reconhecidas, por meio das quais os trabalhadores, mesmo desqualificados, resolvem os problemas derivados das prescrições de trabalho, a partir do que têm amplo poder de intervenção (Jones e Wood, 1984).

Os resultados destas pesquisas, tais como as realizadas por autores anteriormente citados, mostraram que o conhecimento tácito não desaparece com a implantação de novas tecnologias, em particular com as de base microeletrônica, mas muda de qualidade, passando a exigir maior aporte de conhecimentos científicos que não podem ser obtidos somente por meio da prática, senão por meio de cursos sistematizados.

Por um lado, os estudos mostram que a implantação de novas tecnologias de base microeletrônica não prescinde do conhecimento tácito dos operadores mais antigos; ao contrário, os mais experientes, repositórios de conhecimentos tácitos relevantes, assumem papel primordial na implantação de novos sistemas, processos ou equipamentos. Por outro lado, a apropriação de conhecimentos científico-tecnológicos necessários para a implantação de novas tecnologias de base microeletrônica demanda relação permanente e sistematizada com o conhecimento teórico, através do domínio das categorias do trabalho intelectual, o que leva à necessidade de formação sistematizada.

Esta conclusão, ao mesmo tempo que valoriza o conhecimento tácito, contraditoriamente põe os trabalhadores em maior dependência de conhecimentos científicos a serem obtidos por meio de processos formativos escolares e não escolares, o que é indicador de um cenário de aprofundamento da dualidade. Os trabalhadores com dificuldades de requalificação intelectualizada, em decorrência da precarização cultural derivada da origem de classe, tendem ou à exclusão ou à inclusão nos setores mais precarizados nos arranjos flexíveis de força de trabalho.

Vista desta forma, a relação entre conhecimento tácito e conhecimento científico na base microeletrônica não é de oposição, mas sim de articulação dialética, posto que são categorias que se integram aos processos de trabalho flexibilizados, nos quais a prevalência do tácito ou do científico responde à especificidade do trabalho a ser realizado por uma força de trabalho de qualificações diferenciadas, que se articulam para atender às necessidades das cadeias produtivas. Ou, como afirma Antunes (2005, p. 41), “ontologicamente prisioneiros do solo material estruturado pelo capital, o saber científico e o saber laborativo mesclam-se mais diretamente no mundo contemporâneo". Contudo, a transferência das capacidades intelectuais para a maquinaria, como afirma o autor, acentua a transformação do traba-lho vivo em trabalho morto, mas não pode eliminá-lo. 
Llori (2001) reforça este argumento com dados de pesquisa sobre os acidentes industriais, concluindo que é 'no' e 'pelo' trabalho cotidiano e graças à atividade e ao savoir-faire dos trabalhadores em todos os níveis que a maioria dos acidentes latentes não se tornam acidentes ativos. Quando os controles automatizados falham, ou quando o planejador do sistema de controle não previu proteções para um dado evento, o controle dos acidentes depende do conhecimento dos trabalhadores, ou seja, do trabalho vivo. Esta conclusão é no mínimo contraditória com os estudos referentes aos equipamentos técnicos e à segurança das instalações, do ponto de vista da confiabilidade que representa o trabalho morto, resultante da transferência de capacidades intelectuais para máquinas informatizadas. Esta estratégia decorre da suposição da fragilidade do trabalho vivo, que deverá, sempre que possível, ser substituído por dispositivos técnicos de segurança.

Decorre desta afirmação uma importante questão: se, quando os sistemas não funcionam, a confiabilidade depende da subjetividade dos trabalhadores que lhes permite inventar soluções que tragam o sistema para a condição segura, evitando acidentes, como desenvolver este conhecimento tácito, se as experiências cotidianas, que se constituem no fundamento das aprendizagens e das suas transferências para novas situações, são cada vez mais inviabilizadas pela automação? E, na ausência do conhecimento tácito, será suficiente o conhecimento científico, sem a base anterior da experiência de campo? (Kuenzer, 2003b).

\section{As políticas e programas de educação profissional nos anos 2000}

Esta segunda parte do texto tem como objeto as políticas de educação profissional que vêm sendo formuladas no período compreendido entre 1995 e 2007, portanto, no segundo governo do presidente Fernando Henrique Cardoso e no governo do presidente Luiz Inácio Lula da Silva, tendo em vista fornecer elementos para, a partir da análise das suas possibilidades e limites, subsidiar a formulação de propostas que atendam às necessidades dos que vivem do trabalho.

Tem-se como hipótese, a partir dos estudos que temos desenvolvido ao longo dos anos, que estas políticas de educação profissional, formuladas a partir da Lei de Diretrizes e Bases da Educação Nacional, embora pautadas pelo discurso da inclusão dos trabalhadores no mundo do trabalho através da qualificação profissional, não só não surtiram o efeito anunciado como ainda tornaram mais precarizadas as ofertas educativas. 


\section{A crescente privatização apesar do discurso da expansão da oferta pública}

A análise das políticas e propostas de educação profissional, implementadas nos governos Fernando Henrique Cardoso e Luiz Inácio Lula da Silva mostra que elas não se diferenciam no que diz respeito à concepção das relações entre Estado e sociedade civil, que devem se dar através das parcerias entre os setores público e privado.

Estas relações supõem o repasse de parte das funções do Estado para a sociedade civil, acompanhado do repasse de recursos, que, realizados sob o ordenamento jurídico privado, fogem aos controles públicos da União. Em decorrência desta concepção, a prestação de contas dos contratos se dá através de relatórios que procuram comprovar que o produto acordado foi alcançado, não havendo controle dos processos, inclusive sob o ponto de vista contábil. Como já se apontou em outro artigo, à guisa de exemplo, o resultado 'jovens qualificados', dentre os quais 30\% devem ser inseridos no mundo do trabalho previsto em vários do programas de educação profissional do governo Lula, tem se prestado a relatórios meramente formais, sem que se tenha indicadores de quantos foram realmente incluídos, de que forma e com que qualidade; e, por conseqüência, não há indicadores do bom uso dos recursos públicos.

Do ponto de vista do repasse de recursos públicos para a iniciativa privada, no governo Lula não houve avanços no sentido da publicização, permanecendo, e de modo mais intenso, a mesma lógica: o repasse de parte das funções do Estado, e dos recursos, para a sua execução para o setor privado sob a alegação da eficácia e da ampliação da capacidade de atendimento, segundo a concepção do público não estatal a ser operacionalizada pelas parcerias com instituições privadas.

Estudos realizados por Grabowski, Ribeiro e Silva (2003) mostram que aproximadamente dois terços dos recursos do Programa de Expansão da Educação Profissional (Proep) foram destinados a projetos apresentados por instituições comunitárias ou privadas, muitas das quais não cumpriram com os termos contratuais, não concluindo as obras e/ou não implementando os cursos por razões que vão desde o inadequado planejamento, para cuja execução os recursos não eram suficientes, à impossibilidade de contratar professores e técnicos necessários ao funcionamento da escola até a falta de alunos em face da inadequação da oferta, como se observa em relatório de auditoria do Tribunal de Contas da União - TCU (Brasil, 2007).

É interessante observar que, no mesmo relatório, o TCU aponta a necessidade de uma maior integração entre os ministérios da Educação e do Trabalho e Emprego, bem como o aproveitamento dos Planos Estaduais de Educação Profissional (PEPs), como referência para a análise e seleção de cartas consulta relativas a projetos escolares 
do segmento comunitário, avaliando a necessidade de atualização desses planos.

Há, portanto, uma profusão de dados que denunciam o mau uso dos recursos públicos a partir de uma concepção que, implementada no governo anterior, foi assumida e estimulada no governo Lula, e que esconde, sob a defesa do caráter público das ações, a sua realização pelo setor privado, sem que haja elementos que permitam comprovar sua eficácia e efetividade social.

O que os dados revelam é que, sob o discurso da parceria entre o Estado, a sociedade civil e o setor empresarial, a partir do entendimento que as organizações da sociedade civil tendem a obter melhores resultados junto ao público jovem em situação de maior vulnerabilidade social, e que estas instituições são capazes de chegar a lugares aonde o Estado não chega, foram e estão sendo carreados vultosos recursos para o chamado setor comunitário realizar a função do Estado no tocante à educação profissional, sem que haja indicações, através de avaliações conseqüentes, de que os projetos atingem suas finalidades. De modo geral, a oferta gratuita, pelos setores público e comunitário é quantitativamente insignificante e pouco aderente às demandas dos excluídos, cujos resultados não evidenciam outra possibilidade de inclusão senão através da realização de trabalhos precarizados e predominantemente eventuais, segundo a lógica da inclusão subordinada, tal como se vem discutindo neste artigo.

\section{O ordenamento jurídico sobre a educação profissional fornece suporte legal à privatização}

A compreensão desta afirmação fica facilitada através da análise do ordenamento jurídico sobre a educação profissional, que tem dado suporte a esta concepção: os decretos 2.208/97, do governo Fernando Henrique Cardoso, e o decreto 5.154/2004, do primeiro governo Luiz Inácio Lula da Silva.

Ao analisar o novo decreto, indagou-se acerca da sua verdadeira intenção, uma vez que, não obstante revogue formalmente o decreto 2.208/97, na prática não o faz, porque, embora 're-crie' os cursos médios integrados, o que na prática não seria necessário por estarem eles contemplados no parágrafo $2^{\circ}$ do artigo 36 da lei 9.394/96, incorpora todas as modalidades de educação profissional por ele propostas, com pequenas mudanças de denominação.

A hipótese que se levantou desde à época em que ainda circulavam diferentes versões sobre o que depois seria o decreto 5.154/04, facilmente comprovável hoje através das informações disponíveis nos diferentes sis- 
temas de controle, inclusive do Tribunal de Contas da União, é a da manutenção do verdadeiro balcão de negócios em que se transformaram as instituições públicas e privadas de educação profissional, a partir do decreto 2.208/97. Assim, o decreto 5.154/04 ampliou o leque de alternativas com o médio integrado sem que nenhuma das possibilidades anteriores, que favoreceram ações privadas de formação precarizada com recursos públicos, fosse revogada.

O novo decreto, portanto, longe de reafirmar a primazia da oferta pública, viabilizando-a através de políticas públicas, representou uma acomodação conservadora que atendeu a todos os interesses em jogo: do governo, que cumpriu um dos compromissos de campanha com a revogação do decreto 2.208/97; das instituições públicas, que passaram a vender cursos para o próprio governo, e gostaram de fazê-lo, renunciando em parte à sua função, e das instituições privadas, que passaram a preencher, com vantagens, o vácuo criado pela extinção das ofertas públicas.

O ensino médio integrado, que seria uma alternativa para a oferta pública de educação profissional de qualidade integrada à educação básica, ainda não teve, desde a edição do decreto 5.154/04, alocação de recursos para o seu financiamento. Os três estados que se disponibilizaram a realizar uma experiência piloto em 2004, tiveram como única alternativa o financiamento próprio, como fez o Paraná.

Em resumo, o que se está afirmando é que, uma vez procedido o desmonte da oferta pública de educação profissional pelo decreto 2.208/97, e estabelecido o balcão de negócios, dificilmente este processo será revertido. A resistência das agências formadoras às exigências do Plano Nacional de Qualificação - PNQ 2003/2007, que substituiu o Plano Nacional de Qualificação do Trabalhador (Planfor) no governo Lula, mostra, entre outros fatos, que o negócio deixou de ser interessante; como resultado, tem-se menos oferta gratuita oferecida pelo setor privado com recursos públicos e reduzida oferta pública.

O PNQ 2003/2007, ao criticar a falta de efetividade social dos cursos de curta duração oferecidos pelo Planfor, entre outras medidas estendeu a duração dos cursos para 200 horas em média, tendo em vista promover a articulação entre educação básica e profissional através de planejamento pedagógico integrado, a ser implementado pela entidade executora, de modo a incluir conteúdos que discutam cidadania, organização e gestão do trabalho e saúde e segurança.

Na prática, estas medidas tiveram como resultado a dificuldade de efetivação dos cursos a partir de vários fatores, com destaque para a perda de interesse das agências formadoras, que não consideram atrativo o investimento para cursos mais extensos e que integrem conhecimentos básicos, o que não tem feito parte de sua experiência; e para o desinteresse do 
público-alvo que busca alternativas que viabilizem inclusão em curto prazo, com o que é difícil integralizar turmas. Embora não se tenha dados exaustivos, há fortes indicações acerca das dificuldades em usar os recursos disponíveis, embora reduzidos, os quais acabam por vezes não sendo investidos na sua totalidade.

No âmbito do PNQ 2003/2007, foi estabelecido o Programa Nacional de Estímulo ao Primeiro Emprego (PNPE), que abrigou uma profusão de programas de educação profissional para cujo financiamento foram abertos inúmeros canais de repasse de recursos para o setor privado, sob a coordenação de diferentes ministérios e da Secretaria Geral da Presidência da República. Em artigo recente, identificamos pelo menos 12 programas em andamento, no setor privado e/ou comunitário, muitos praticamente idênticos, mas sob a coordenação de órgãos diferentes, que repassaram vultosos recursos públicos para a sua execução (Kuenzer, 2006).

Verifica-se, portanto, que o repasse dos recursos públicos para o setor privado tem suporte na legislação, elaborada para atender a uma determinada concepção de Estado, que se operacionaliza através de parcerias público-privadas, as quais visam à execução, pelo setor privado, de parte significativa das funções públicas.

\section{A ausência de políticas públicas}

Além da concepção de ação pública não estatal, que tem justificado o repasse de recursos públicos para instituições privadas, os programas referenciados se caracterizaram pela desarticulação e pela fragmentação das ações a que deram origem, através de uma profusão de projetos similares espalhados por diferentes unidades gestoras.

Com o objetivo de viabilizar cada um desses programas, são estabelecidas parcerias entre a Secretaria Geral da República, ministérios, governos estaduais, municipais e outros órgãos federais, entidades da sociedade civil, empresas públicas e privadas, sempre prevalecendo o repasse dos recursos públicos ao setor privado, através das redes ou franquias sociais. E de modo geral, eles são muito parecidos, com pequenas especificidades que não justificam tamanha fragmentação de ações e pulverização de recursos. Como resultado, reproduzem-se estruturas, espaços e recursos, financeiros e humanos, para os mesmos fins, configurando-se uma clara estratégia populista de eficácia discutível.

Não é de estranhar, portanto, a reivindicação feita pelos gestores públicos da educação profissional, para que estes inúmeros projetos que fragmentam as ações e os recursos, executados pelo setor privado, sejam substituídos por uma política de Estado que contemple, de forma orgânica, 
o financiamento e a gestão pública, comprometidos com o bom uso dos recursos públicos, a ser assegurado pelos controles públicos da União, posto que há dados que permitem questionar falta de efetividade social dos programas que vêm sendo desenvolvidos, que se revestem de caráter fragmentado, assistencialista e compensatório, sem que se configurem de fato como política pública.

Um bom exemplo do caráter populista destas políticas, propostas sem cuidadoso estudo da realidade do mundo do trabalho, é a notícia veiculada na imprensa (Folha Online, 2007) que mostra que, após quatro anos de fracassos sucessivos, o governo Lula enterrou o Programa Primeiro Emprego, que dava vantagens a empresas que oferecessem vagas a jovens de 16 a 24 anos, por falta de interesse. Segundo a reportagem, "em março de 2004, o sistema eletrônico de acompanhamento dos gastos federais registrava um único beneficiário, um jovem contratado como copeiro por um restaurante de Salvador". Ao mesmo tempo que este programa, uma das meninas dos olhos do governo Lula, é extinto, a Secretaria de Educação Tecnológica do MEC, Setec, está desenvolvendo estudos para integrar programas e propostas e o governo recupera o financiamento no ensino técnico ${ }^{2}$ (Folha Online, 2007), o que pode ser um indicador da substituição da oferta de programas fragmentados por políticas de longo prazo, privilegiando a esfera pública. Há, contudo, que aguardar as propostas e avaliar os resultados, antes de emitir julgamentos de valor.

Como já se afirmou em outro texto, a razão fundamental para que a política de educação profissional seja uma política de Estado, é o reconhecimento do papel estratégico que desempenham a educação e a produção do conhecimento científico-tecnológico e sócio-histórico no processo de construção de uma sociedade de novo tipo, fundada na justiça social a partir da participação de todos na produção, na fruição do que foi produzido, na cultura e no poder, o que demanda processos educativos que articulem formação humana e sociedade na perspectiva da autonomia crítica, ética e estética (Kuenzer e Grabowski, 2006).

\section{Percursos aligeirados e desvalorização do conhecimento científico como expressão da nova epistemologia da prática}

A análise das propostas de educação profissional que vêm sendo levada a efeito, a partir dos dados disponibilizados pelas pesquisas de campo que temos realizado nos últimos anos, vem evidenciando que, embora as mudanças ocorridas no mundo do trabalho passem a exigir ampliação da educação básica com qualidade, à qual se integre formação profissional de natureza tecnológica, fundada no domínio intelectual da técnica 
enquanto relação entre conhecimentos e competências cognitivas complexas, o que se vem oferecendo aos que vivem do trabalho se resume, basicamente, à reprodução do conhecimento tácito.

Assim é que os projetos contemplam um amálgama de qualificação social entendida como ação comunitária, aprendizagem de fragmentos do trabalho no espaço produtivo como conhecimento científico-tecnológico, domínio de algumas ferramentas da informática e das linguagens como capacidade de trabalho intelectual, discussão sobre algumas dimensões da cidadania como capacidade de intervenção social, levando a entender que o resultado deste conjunto configura-se como educação para a inclusão social. Embora estes elementos sejam fundamentais para a educação dos que vivem do trabalho, a forma superficial e aligeirada, na maioria das vezes descolada da educação básica de qualidade, reveste as propostas de caráter formalista e demagógico, a reforçar o consumo predatório da força de trabalho ao longo das cadeias produtivas.

De modo geral, os projetos pedagógicos dos programas propostos no governo Lula contemplam 600 horas de formação, distribuídas com pequenas variações conforme a especificidade de cada projeto, tendo em vista o desenvolvimento do jovem enquanto pessoa, cidadão e trabalhador. Deste total, geralmente 200 horas são destinadas à qualificação profissional e 100 horas à formação em cidadania e direitos humanos. As demais 300 horas correspondem à contrapartida da entidade, realizada através de serviços prestados ao projeto nas seguintes atividades: supervisão das ações de prestação de serviços voluntários à comunidade; ações de estímulo e apoio à elevação de escolaridade; ações de inserção dos educandos no mundo do trabalho.

Ou seja, um projeto de 600 horas inclui na realidade 300 horas específicas de atividades de formação, mais as horas dedicadas à prestação de serviços voluntários, que variam entre 75 e 125 horas. Com relação à freqüência à escola, de modo geral os alunos se matriculam em ofertas regulares ou supletivas para entrar e manter-se no programa, abandonando a escola em seguida; as relações entre o programa de educação profissional e a escola são muito tênues, quando existem.

Não há, portanto, nos programas de educação profissional, referência e condições concretas, dadas as suas características, para a implementação de procedimentos pedagógicos que assegurem o desenvolvimento das competências complexas que caracterizam o trabalho intelectual. Em particular as que assegurem o exercício da crítica, da criação, da participação política ou acesso aos conhecimentos necessários para enfrentar os desafios de uma sociedade cada vez mais excludente, para o que o domínio de conhecimentos científicos, tecnológicos e sócio-históricos, com vistas à formação de um profissional com autonomia intelectual e ética, são fundamentais. 
A idéia que fundamenta estes modelos é que a prática profissional consiste na solução instrumental de problemas mediante a aplicação de um conhecimento previamente disponível; basta, portanto, dar acesso a algumas técnicas elementares que conduzam a resultados esperados para que a formação profissional se efetive. Permanecemos, portanto, no âmbito da formação precarizada para tarefas simplificadas.

\section{Por contradição, a extensão da escolarização com qualidade e integrada é a mediação necessária: rumo à politecnia?}

Ao analisar as novas demandas de educação profissional, derivadas das mudanças na base técnica com a crescente utilização da microeletrônica, que demandam cada vez mais domínio das categorias referentes ao trabalho intelectual em contraposição à centralidade do conhecimento tácito, típica do taylorismo/fordismo, tem-se afirmado que, ao tempo em que as pesquisas levem a estas constatações, as políticas públicas em vigor para todos os níveis de ensino propõem como tarefa à escola o desenvolvimento de competências entendidas como capacidades de realizar tarefas práticas, desvalorizando, e mesmo declarando desnecessário, o conhecimento científico. Assim é que são traduzidas as competências no ensino médio, na educação profissional e nos cursos de graduação, onde os percursos curriculares tendem a ser encurtados, à luz dos princípios pós-modernos que negam a objetividade da ciência e o caráter histórico da produção do conhecimento, ao mesmo tempo em que propõem a ampliação dos espaços da prática, na esperança que a mera inserção do aluno no processo de trabalho seja suficiente para a sua formação (Kuenzer, 2003a).

A pedagogia do trabalho, assim compreendida, se resume a observar e repetir até memorizar as 'boas práticas' dos trabalhadores mais experientes, bastando inserir desde logo o trabalhador na situação concreta de trabalho, mesmo antes que ele se aproprie de categorias teórico-metodológicas que lhe permitam analisá-la e compreendê-la para poder intervir com competência.

Restaria perguntar, portanto, a quem interessa reduzir a formação ao conhecimento tácito através de uma epistemologia na qual a prática se constrói através de uma reflexão sobre si mesma, sem a mediação da teoria, desqualificando-se os espaços onde os que vivem do trabalho poderiam ter acesso ao conhecimento científico, tecnológico e sócio-histórico, enquanto produto do pensamento humano, mas também enquanto método para aprender a conhecer?

De qualquer modo, estas conclusões trazem ao debate o caráter mediador da ação educativa, mediante a qual se articulam teoria e prática, no 
plano do pensamento e por meio do trabalho intelectual, de modo a permitir a compreensão e sistematização do conhecimento tácito e sua transformação em conhecimento científico. Justifica-se, deste modo, o resgate das ações educativas sistematizadas, escolares e não escolares, pelo regime de acumulação flexível.

A análise realizada, embora com dados preliminares, indica um extenso programa de investigação a ser levado a efeito por aqueles intelectuais que professam compromisso com os que vivem do trabalho, tendo em vista a avaliação do que se lhes tem ofertado sob o discurso de sua inclusão, a proposição coletiva de projetos de outra natureza. E mostra que os princípios que orientaram a educação profissional no governo Fernando Henrique não foram superados no governo Lula, alguns deles inclusive tendo sido intensificados.

Alguns elementos de realidade permitem elencar hipóteses, para algumas das quais já se tem bons indicadores acerca de seu potencial explicativo: a destruição progressiva das ofertas públicas em nome do repasse de parte das funções do Estado para a sociedade civil, em face não só de sua impossibilidade de realizá-las, mas principalmente de uma maior competência do setor privado; a enunciação apenas formal, na maioria dos projetos, da integração da proposta à educação básica; o caráter genérico, não profissional, da maioria dos projetos de educação profissional; a ênfase no conhecimento tácito em detrimento do acesso ao conhecimento científicotecnológico e sócio-histórico, negado em nome de seu pretenso caráter racionalista; a pulverização de ações e de recursos a atender a uma proposta populista, em substituição a uma proposta orgânica e consistente, de política de Estado.

Como resultado, é possível indicar a continuidade de propostas precárias de educação profissional para legitimar a inclusão em trabalhos precarizados, de modo a alimentar o consumo predatório da força de trabalho, cuja subjetividade tenha sido reduzida ontologicamente pelos processos sociais e econômicos de flexibilização justificados por processos educativos que apresentam a possibilidade de sucesso na sociedade flexível através da capacidade de empreender, de criar, a partir da ausência de direitos.

O que leva a refletir que, na sociedade capitalista, em que se que produzem relações sociais e produtivas que têm a finalidade precípua de valorização do capital, não há inclusão que não atenda a esta lógica, como não há possibilidade de existência de práticas pedagógicas autônomas; apenas contraditórias, cuja direção depende das opções políticas que definem os projetos, seus financiamentos e suas formas de gestão. O desafio que se coloca é o rompimento deste círculo, o que demanda novas leituras e propostas a partir de práticas que apontem para novas formas de organização social, 
que interfiram positivamente no atendimento às necessidades dos que vivem do trabalho.

\section{Notas}

1 Professora Titular aposentada da Universidade Federal do Paraná, Curitiba, Brasil, e pesquisadora 1C do Conselho Nacional de Desenvolvimento Científico e Tecnológico (CNPq), Brasília, DF. Doutora em Educação pela Pontifícia Universidade Católica de São Paulo.<acaciazk@uol.com.br>

Correspondência: Rua José de Alencar, 161, apto. 114, Curitiba, Paraná, Brasil, CEP 80050240.

2 O MEC pretende injetar nos próximos três anos mais de R \$ 2 bilhões na ampliação e melhoria do ensino técnico brasileiro. O projeto faz parte da segunda fase do Plano de Expansão da Rede Federal de Educação Profissional, que será colocada em prática a partir do próximo ano.

\section{Referências}

ANTUNES, Ricardo. Trabalho e superfluidade. In: SAVIANI, Dermeval; SANFELICE, José Luís; LOMBARDI, José Claudinei (Orgs.). Capitalismo, trabalho e educação. 3.ed. Campinas: Autores Associados, 2005. p. 35-44.

BRASIL. Tribunal de Contas da União. Acórdão n ${ }^{\circ}$ 956/2004, da $2^{\text {a }}$ Câmara. Secretaria Geral das Sessões, Ata n. 34 de 9 de setembro de 2004. Relatório de Auditoria. Disponível em: <www.tcu.gov.br/SA/ RoldeAtas>. Acesso em: 19 out. 2007.

FOLHA ONLINE. Dinheiro, 31 ago. 2007. Disponível em: <www.uol.com.br/ folhaonline/dinheiro $>$. Acesso em: 31 ago. 2007.
GRABOWSKI, Gabriel; RIBEIRO, Jorge.; SILVA, Daniel. Formulação de politicas de financiamento da Educação Profissional no Brasil. Brasília: Proep/Semtec/MEC, 2003.

GRAMSCI, Antonio. Os intelectuais e a organização da cultura. Rio de Janeiro: Civilização Brasileira, 1978.

JONES, Bryn; WOOD, Stephen. Qualificações tácitas, divisão do trabalho e novas tecnologias. Sociologia du travail, Paris, n. 4, 1984.

KUENZER, Acacia. Competência como práxis: os dilemas da relação entre teoria e prática na educação dos trabalhadores. 
Boletim Técnico do Senac, Rio de Janeiro, v. 29, n. 1, jan./abr. 2003 a.

As relações entre conhecimento tácito e científico a partir da base microeletrônica: primeiras aproximações. Educar em Revista, Curitiba, n.l (Especial), p. 43-70, 2003b.

Exclusão includente e inclusão excludente: a nova forma de dualidade estrutural que objetiva as novas relações entre educação e trabalho. In: SAVIANI, Dermeval; SANFELICE, José Luís; LOMBARDI, José Claudinei. (Orgs.). Capitalismo, trabalho e educação. 3. ed. Campinas: Autores Associados, 2005. p. 77-96.

A educação profissional nos anos 2000: a dimensão subordinada das políticas de inclusão. Educação e Sociedade, v. 27, p. 877-910, 2006.
Da dualidade assumida à dualidade negada: o discurso da flexibilização justifica a inclusão excludente. Educação e Sociedade, v. 28, p.1-25, 2007. No prelo.

; ABREU, Cláudia. Barcelos de Moura ; GOMES, Cristiano. Mauro Assis. A articulação entre conhecimento tácito e inovação tecnológica: a função mediadora da educação. Revista Brasileira de Educação, v. 12, p. 1-16, 2007.

GRABOWSKI, Gabriel. Educação profissional: pressupostos para a construção de um projeto para os que vivem do trabalho. Perspectiva, Florianópolis, v. 24, p. 297318, 2006.

LLORI, Michel. Acidentes industriais: o custo do silêncio. Rio de Janeiro: Multiação, 2001.

OLIVEIRA, Avelino. Marx e a exclusão. Pelotas: Seiva, 2004. 